\title{
Extreme tachycardia complicating the use of disopyramide in atrial flutter
}

\author{
COLIN E ROBERTSON, HUGH C MILLER \\ From the Coronary Care Unit, Royal Infirmary, Edinburgh
}

SUMMARY A 59-year-old man presented with atrial flutter and a 2:1 atrioventricular response, which, after intravenous disopyramide, became 1:1. A mechanism of slowed atrial flutter rate and improved atrioventricular nodal conduction, similar to that recognised with quinidine, is suggested.

Disopyramide is an antiarrhythmic drug which has pharmacological properties similar to quinidine ${ }^{12}$ and a wide spectrum of efficacy. It has been advocated for the treatment of virtually all supraventricular tachyarrhythmias, including atrial flutter. With few exceptions it has been well tolerated, but dose-related anticholinergic side effects are occasionally troublesome. There has been a report of disopyramide toxicity complicated by ventricular tachycardia ${ }^{3}$ but in the case reported here acute administration of disopyramide in normal doses to a patient with atrial flutter resulted in a life-threatening tachycardia. Similar responses have been previously associated with quinidine and this occurrence with disopyramide is not unexpected.

\section{Case history}

A 59-year-old labourer presented with a three-week history of dyspnoea on exertion, palpitation, and ankle swelling. Four years previously he had been admitted to another hospital with similar symptoms and had been treated with cardioversion. His daily alcohol intake was in excess of 16 pints of beer; he smoked 40 cigarettes a day and had a 15-year history of chronic bronchitis. He had taken no drugs before admission.

On examination he was obese, plethoric, and undistressed. He had a regular tachycardia of 160 per minute, without a pulse deficit; the blood pressure was $165 / 120 \mathrm{mmHg}$. The jugular venous pressure was raised above the angle of the jaw; there was moderate dependent oedema and fine bilateral basal crepitations were present.
A 12 lead electrocardiogram showed atrial flutter with 2:1 atrioventricular block and a ventricular rate of 160 per minute (Fig. trace A), The chest $x$-ray film disclosed cardiomegaly and pulmonary venous congestion.

He was admitted to the coronary care unit. The arrhythmia failed to respond to carotid sinus massage and the Valsalva manoeuvre. Subsequently disopyramide phosphate was given by slow intravenous injection at a rate of $10 \mathrm{mg}$ per minute. After the administration of $80 \mathrm{mg}$ he developed short runs of atrial flutter with $1: 1$ atrioventricular conduction and a ventricular rate of 240 per minute with no change in QRS morphology. The infusion was discontinued. This rhythm (Fig. trace B) persisted, however, and he rapidly lost consciousness and had a grand mal convulsion. He was immediately cardioverted, initially unsuccessfully at $100 \mathrm{~J}$ followed by successful cardioversion at $200 \mathrm{~J}$, with restoration of normal sinus rhythm at a rate of 90 per minute. There was prompt improvement in his perfusion and he regained consciousness shortly thereafter.

Further investigations confirmed that he was euthyroid. There was no clinical or echocardiographic evidence of valvular disease. Standard 12 lead electrocardiograms were within normal limits with no evidence of pre-excitation or anomalous atrioventricular conduction. His liver function tests were deranged with bilirubin $20 \mathrm{nmol} / 1$ (normal 2 to $17 \mathrm{nmol} / \mathrm{l}$ ) and serum gamma glutaryl transferase 82 units/1 (normal 10 to 55 units/1). These investigations were compatible with his excessive alcohol consumption and he was presumed to have an alcoholic cardiomyopathy.

Nine months after this episode he remains well, 
Lead V1

A

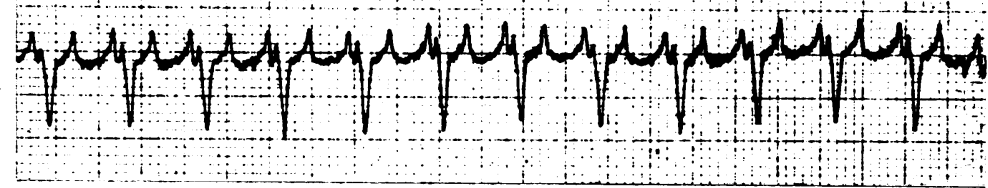

B

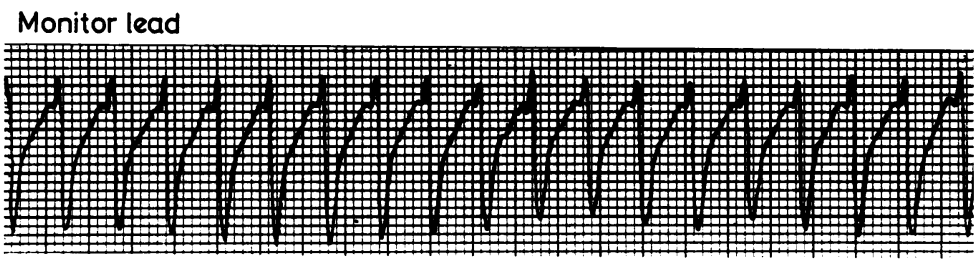

Fig. Electrocardiogram: (A) shows atrial flutter with $2: 1$ atrioventricular conduction and ventricular rate 160 per minute; (B) after $80 \mathrm{mg}$ disopyramide intravenously over eight minutes. The different $Q R S$ morphology is the result of the different electrocardiographic lead recorded. in atrial fibrillation, with a ventricular rate controlled on digoxin alone.

\section{Comment}

The effect of disopyramide on atrioventricular nodal conduction is variable, probably because of varying vagal tone, but enhancement of conduction occurs in some patients. ${ }^{5}$ Recently it has been shown that intravenous disopyramide slows the atrial rate in patients in whom atrial flutter has been initiated by atrial pacing. ${ }^{6}$ We believe that in our case the administration of disopyramide slowed the atrial flutter rate from 320 per minute to 270 per minute, while improving atrioventricular nodal conduction, thus allowing a 1:1 atrioventricular response. A similar electrophysiological mechanism is well recognised with quinidine ${ }^{4}$ and before treating atrial flutter or atrial fibrillation with quinidine prior treatment with digoxin has been recommended to decrease atrioventricular node conduction time and to increase the degree of atrioventricular block, thus preventing a rapid ventricular response. Disopyramide and quinidine are very similar drugs so this complication with disopyramide is not unexpected. Like quinidine, therefore, we would advocate that disopyramide is contraindicated in the treatment of atrial flutter or atrial fibrillation unless atrioventricular conduction is slowed by prior treatment with digoxin or a beta-blocker. Atrial flutter is at times difficult to identify as the cause of supraventricular tachycardia so this possibility should be entertained before administering disopyramide indiscriminately for supraventricular tachyarrhythmias.

\section{References}

1 Hall RC, Brogden RN, Spreight TM, Avery GS. Disopyramide. A review of its pharmacological properties and therapeutic use in treating cardiac arrhythmias. Drugs 1978; 15: 331-68.

2 Josephson ME, Caracta AR, Lau SH, Gallagher JJ, Damato AN. Electrophysiological evaluation of disopyramide in man. Am Heart $\mathcal{f} 1973$; 86: 771-80.

3 Meltzer RS, Robert EW, McMorrow M, Martin RP. Atypical ventricular tachycardia as a manifestation of disopyramide toxicity. Am f Cardiol 1978; 42: 1049-53.

4 Laurence DR. Clinical pharamacology. 2nd ed. London: J \& A Churchill, 1963: 334.

5 Befeler B, Castellanos A Jr, Wells DE, Vagueiro MC, Yeh BK. Electrophysiologic effects of the antiarrhythmic agent disopyramide phosphate. Am $\mathcal{F}$ Cardiol 1975; 35: 282-7.

6 Camm J, Ward D, Spurrell RAJ. Response of paroxysmal atrial flutter to intravenous disopyramide phosphate and overdrive atrial pacing (abstract). Br Heart f 1979; 42: 237.

Requests for reprints to Dr Colin E Robertson, Medical Renal Unit, The Royal Infirmary, Edinburgh EH3 9YW. 